\title{
Notas sobre los Principios de Competencia y de Prevalencia en la Legislación Compartida
}

\author{
Jesús Leguina Villa \\ Catedrático de Derecho Administrativo \\ Universidad de Alcalá de Henares
}

El modelo español de descentralización política se define, en lo esencial, por las reglas constitucionales y estatutarias que regulan la distribución del poder legislativo y las relaciones entre el ordenamiento estatal (general) y los ordenamientos autonómicos (singulares).

Aunque el sistema autonómico español ofrezca otras muchas peculiaridades en comparación con otros Estados descentralizados (por ejemplo: diferentes vías de acceso a la autonomía política; amplio repertorio tipológico de Comunidades Autónomas; elevado grado de vigencia del principio dispositivo; diferentes títulos constitucionales de las competencias autonómicas: Estatutos, derechos históricos; etc.), son en definitiva aquellas reglas las que determinan el ubi consistam de la opción del constituyente español y las que, en consecuencia, marcan las diferencias que distancian tal opción de otros tipos o modelos de Estados territorialmente descentralizados. El objeto de estas breves notas no es dar cuenta de tales diferencias entre unos y otros modelos constitucionales de organización territorial del Estado, vistas desde la perspectiva del poder de legislar y de las relaciones entre las distintas fuentes normativas territoriales 1 , sino más modestamente, ofrecer una sucinta reflexión sobre el control de los conflictos normativos que se suscitan en el ámbito de las competencias legislativas compartidas entre el Estado y las Comunidades Autónomas. Al hilo de dicha reflexión se aludirá, no obstante, a algunas de aquellas diferencias.

El criterio constitucional predominante en la distribución de competencias normativas entre el Estado y las Comunidades Autónomas es el criterio de la compartición. Predominante, aunque no único, pues, como es notorio, la Constitución reserva a la competencia exclusiva del

\footnotetext{
1 Un excelente estudio de los principales modelos que ofrece el Derecho Comparado, subrayando las peculiaridades de cada uno y sus diferencias con el sistema autonómico español, en A. BAYONA ROCAMORA, El derecho a legislar en el Estado Autonómico, Ed. Tecnos, Madrid 1992.
} 
Estado (de todas las funciones o, al menos, de la función legislativa) un buen número de materias, entre ellas todas las que tradicionalmente simbolizan la soberanía nacional (relaciones internacionales, defensa, sistema monetario, hacienda general, etc.), al tiempo que autoriza a que por vía estatutaria las Comunidades Autónomas asuman la potestad de legislar en exclusiva sobre otro grupo de materias, ciertamente menos numeroso y de menor importancia política. Tampoco es completamente desconocido al modelo autonómico español el criterio de la legislación concurrente (konkurrierende Gesetzgebung), característico de los sistemas federales, aun cuando, a diferencia de éstos, el lugar que tal criterio ocupa en el esquema competencial sea marginal y poco significativo 2 .

El eje del sistema de producción normativa, su modalidad más peculiar y característica, lo constituye, pues, la legislación compartida entre el Estado y las Comunidades Autónomas, en virtud de la cual aquél aprueba las normas básicas de una determinada materia y éstas dictan las normas complementarias o de desarrollo, de manera que el régimen jurídico resultante es compartido por las normas estatales en lo básico y por las normas autonómicas en lo no básico o complementario. El sistema se vertebra, por tanto, sobre el principio de competencia que es el que traza la línea divisoria entre unas y otras normas en razón de la distinción de los aspectos básicos y no básicos en la regulación de una determinada materia ${ }^{3}$, operando de este modo dicho principio como canon de su validez constitucional.

Ahora bien, desde el momento en que el Tribunal Constitucional sostuvo la tesis de que la legislación básica del Estado pudiera consistir no sólo en un conjunto de principios sin eficacia directa, destinado al

\footnotetext{
2 El supuesto más destacado - para muchos autores el único- que la Constitución ofrece de legislación concurrente es el que se contiene en el art. 149.2 relativo a la materia "cultura». Y aun en este caso hay quien opina que tampoco la concurrencia legislativa del Estado y de las Comunidades Autónomas es perfecta o indistinta, pues no siempre ni necesariamente la ley estatal posterior desplaza a la ley autonómica anterior. Ver en tal sentido las atinadas reflexiones de BAYONA, op. cit., pág 132 y ss.

3 Considera el Prof. BALAGUER CALLEJÓN en su excelente obra Fuentes del Derecho, vol. II, Ordenamiento general del Estado y ordenamientos autonómicos, Ed. Tecnos, Madrid 1992, que más que de una división competencial sobre dos partes de una misma materia debe hablarse de una distinción en la propia competencia normativa del Estado y de la Comunidad Autónoma, ya que "la competencia no recae sobre la materia, sino sobre una fase específica del tratamiento normativo de esa materia" (pág. 243). Sin embargo, el resultado a que se llega es el mismo, háblese de materia compartida por la legislación básica del Estado y complementaria de la Comunidad Autónoma, o de competencia legislativa compartida entre el Estado y las Comunidades Autónomas, limitada la de aquél a la regulación básica y la de éstas a la regulación complementaria.
} 
legislador autonómico, sino también - y principalmente- en normas o preceptos inmediatamente aplicables que establecieran «la regulación normativa uniforme y de vigencia en toda la Nación» 4 , la legislación en régimen de compartición, eje central del sistema de producción normativa en el Estado Autonómico, adquirió de golpe un elevado grado de complejidad, haciendo sumamente difícil tanto la función delimitadora entre normas básicas y complementarias que ha de cumplir el principio de competencia, como su control jurídico por el Tribunal Constitucional, dado que lo que haya de entenderse por regulación "básica» es por fuerza una noción relativamente indeterminada o abierta, cuyo alcance habrá de ser distinto en cada materia y cuya determinación puede sufrir variaciones según las circunstancias concurrentes en cada momento o, simplemente, según las oscilaciones que sufra la mayoría parlamentaria ${ }^{5}$.

Ha sido, pues, inevitable que, sin tradición en este modo de legislar (la Constitución republicana desconocía esta figura de reparto competencial) y careciendo el Senado de todo protagonismo en este campo, dadas su actual composición y funciones, se haya producido un elevado número de conflictos entre el Estado y las Comunidades Autónomas en el ámbito, precisamente, de las materias que la Constitución y los Estatutos han entregado a la legislación compartida entre ambas fuentes territoriales. Junto a ello, y al cabo de casi quince años de ejercicio por el Estado de sus potestades normativas básicas, empiezan a no ser infrecuentes los supuestos en que el legislador estatal, al modificar su legislación básica, entra en colisión con la vigente legislación autonómica complementaria. ¿Cómo se resuelve esta colisión? ¿Qué principios constitucionales deben aplicarse? Y sobre todo: ¿cabe residenciar el conflicto normativo ante los tribunales ordinarios o tal cometido es, por el contrario, función exclusiva de la jurisdicción constitucional?

Las respuestas que se han venido dando a tales cuestiones dependen directamente del modo de entender el alcance del principio de prevalencia del Derecho del Estado que el art. 149.3 de la Constitución consagra. Veamos, pues, cuáles son las principales posiciones doctrinales al respecto.

\footnotetext{
4 Doctrina reiterada en múltiples ocasiones desde la STC, 1/1982, pero matizada, en lo que concierne a la Comunidad Autónoma Vasca y a la Comunidad Foral de Navarra, que ostentan competencias derivadas de sus derechos históricos amparados por la Disposición Adicional primera de la Constitución, en las Sentencias 214/1989 y 140/1990.

5 Algún autor ha llegado a negar que haya criterios jurídicos para juzgar sobre opciones acerca de lo básico que son de naturaleza estrictamente política. Así, por ejemplo, I. DE OTTO, Derecho Constitucional. Sistema de fuentes, Ed. Ariel, Barcelona 1987, pág. 280.
} 
Hay quien sostuvo tempranamente que la regla de la prevalencia del art. 149.3 de la Constitución es pura y simplemente una norma de competencia favorable al Derecho estatal que debe aplicarse a todos los conflictos que se susciten entre las normas estatales y las normas autonómicas en las materias compartidas del art. 149.1 de la Constitución 6 .

La mayor parte de los autores considera, sin embargo, que la regla de la prevalencia es estrictamente una norma de conflicto. ¿Pero qué conflictos debe resolver? ¿En qué casos de colisión normativa se ha de dar preferencia a las normas del Estado sobre las normas autonómicas? Aquí las respuestas varían mucho, casi tanto como los autores que se han pronunciado sobre el asunto, pero en términos generales pueden reducirse a dos: 1) la de quienes entienden que la regla de la prevalencia debe utilizarse cuando se haya apurado sin éxito la aplicación del principio de competencia, lo que podría ocurrir en tres supuestos: a) en materias de competencias concurrentes; b) en materias de competencias compartidas entre la legislación estatal y la legislación autonómica conforme al binomio «bases-desarrollo"; y c) en materias en las que se produzca un entrecruzamiento o superposición de títulos competenciales estatales y autonómicos sobre un mismo objeto. Y 2) la de quienes sostienen que el alcance de la primacía de las normas estatales sólo es constitucionalmente posible en los limitados supuestos de colisión normativa que se produzcan en las materias susceptibles de la legislación concurrente del Estado y de las Comunidades Autónomas 7 .

Para esta última posición doctrinal, que me parece sólidamente fundada, la regla de la prevalencia sólo puede operar cuando la ley estatal y la ley autonómica que entran en conflicto se ajustan al orden constitucional de distribución de competencias, es decir, cuando ambas normas son válidas pero incompatibles entre sí, lo que únicamente puede ocurrir en los escasos y marginales supuestos de concurrencia competencial que nuestro ordenamiento constitucional admite, puesto que, como hace notar con toda claridad Fernández Farreres, «si la colisión

\footnotetext{
6 Es la pionera posición mantenida por L. PAREJO ALFONSO, La prevalencia del Derecho estatal sobre el regional, Madrid, 1981. Aunque con un razonamiento distinto y llegando a conclusiones muy diferentes, recientemente califica también como norma de competencia a la regla de la prevalencia BALAGUER CALLEJÓN, op. cit., págs. 237-239.

${ }^{7}$ Puede verse una detallada exposición de las diferentes opiniones doctrinales sobre el alcance del principio de prevalencia en I. LASAGABASTER HERRARTE, Los principios de supletoriedad y prevalencia del Derecho estatal respecto al Derecho autonómico, Ed. Civitas, Madrid 1991.
} 
normativa surgiese como consecuencia del ejercicio por una de las partes de una competencia que viola o infringe el orden competencial constitucionalmente establecido, es obvio que a la prevalencia ninguna función correspondería, ya que una de las normas en colisión incurrirá en inconstitucionalidad por vicio de incompetencia» ${ }^{8}$. Quiere ello decir que la prevalencia del Derecho estatal no altera el orden constitucional de competencias ni juega en contra del principio de competencia sino sólo en su defecto, lo que impide que sea aplicable tanto a los casos de colisión normativa que se produzcan en el ejercicio de competencias legislativas compartidas, como a los supuestos de superposición o entrecruzamiento de títulos competenciales ratione materiae, conflictos normativos todos ellos que deben resolverse sin excepción alguna, cualquiera que sea la dificultad que ello ofrezca, mediante la aplicación del principio de competencia.

Volviendo ahora a los poderes de control de la jurisdicción ordinaria, no es dudoso que, en caso de colisión entre una ley estatal y otra autonómica, válidamente dictadas en la regulación de una materia de competencia legislativa concurrente, los jueces deberán hacer uso de la regla de la prevalencia para aplicar la ley estatal válida e inaplicar la también válida ley autonómica. Sobre este punto la opinión doctrinal es unánime. Pero ¿cabe sostener lo mismo respecto de los conflictos que se produzcan, en materias de competencia normativa compartida, entre una ley básica estatal y una ley complementaria autonómica? La cuestión reviste una extraordinaria importancia constitucional, pues se trata nada menos que de mantener intacto, como hasta ahora, el monopolio del control de constitucionalidad de todas las leyes posteriores a la Constitución en el Tribunal Constitucional o, por el contrario, de dar paso a un sistema de control judicial difuso en lo tocante a la constitucionalidad de las leyes autonómicas complementarias de la legislación básica del Estado.

Como antes indicaba, las respuestas doctrinales que a esta grave cuestión se han dado están muy condicionadas por el alcance que se otorgue a la regla de la prevalencia. Dicho en otros términos, si se admite la aplicación de dicha regla constitucional en el ámbito de la legislación compartida, la respuesta será afirmativa; por el contrario, si se rechaza tal aplicación y se entiende que ésta sólo es posible en el limitado campo de la concurrencia legislativa, la respuesta será forzosamente negativa.

8 "Colisiones normativas y primacía del Derecho estatal» en Estudios sobre la Constitución española. Homenaje al Profesor Eduardo Garcla de Enterría, vol. I, Ed. Civitas, Madrid 1991, pág. 541. 
Los partidarios del control judicial sostienen que la ley básica estatal es una ley superior a la ley autonómica, tiene «más valor» normativo, y por ello, en caso de conflicto, el juez ordinario está más fuertemente vinculado a la ley básica estatal que a la ley autonómica complementaria, razón por la cual deberá aplicar aquélla y desconocer e inaplicar esta última. En defensa de esta postura se matiza, para evitar equívocos, que la superioridad de la ley básica estatal no es jerárquica o de rango sino sólo funcional: es superior la función que la Constitución encomienda a la ley del Estado - crear una regulación uniforme que asegure, en aras de los intereses generales, un denominador común normativo en todo el territorio nacional- que la que cumple la ley autonómica al expresar y garantizar los intereses propios de la Comunidad Autónoma. Ello bastaría, según esta opción, para asegurar la prevalencia de la ley básica estatal en caso de conflicto con la ley autonómica complementaria, mediante la utilización de la regla del art. 149.3 de la Constitución. Tal superioridad funcional permitiría al juez ordinario, con apoyo en la regla de la prevalencia, aplicar la ley básica estatal e inaplicar la ley autonómica complementaria que la contradiga ${ }^{9}$. Es cierto que el juez ordinario podría en tal caso promover la correspondiente cuestión de inconstitucionalidad ante el Tribunal Constitucional, pues a ello le autoriza el art. 163 de la Constitución, pero no estaría obligado a hacerlo, pues, según esta posición doctrinal, la superioridad funcional de que goza la ley básica estatal permite también al juez decidir por sí mismo el conflicto normativo en favor de esta última mediante la aplicación pura y simple de la regla de la prevalencia del Derecho estatal sobre el Derecho autonómico. En definitiva, según esta tesis, la Constitución ofrece dos posibilidades a los jueces y tribunales ordinarios: plantear la cuestión de inconstitucionalidad para que decida el Tribunal Constitucional; o resolver por sí mismos el conflicto normativo mediante la aplicación de la regla de la prevalencia (arts. 163 y 149.3 de la Constitución, respectivamente).

En mi opinión, no es posible suscribir esta posición, aunque se comparta por completo el propósito que la anima de buscar en otras

\footnotetext{
9 Tal es la opinión de R. GÓMEZ-FERRER, «Relaciones entre leyes: competencia, jerarquía y función constitucional», RAP 113, 1987. En sentido análogo y aun en términos más radicales, mantiene también una posición netamente favorable al control judicial ordinario de esta clase de conflictos internormativos F. RUBIO LLORENTE, El bloque de la constitucionalidad, Cuadernos Civitas, Madrid 1991, pág. 131: «Las leyes autonómicas que regulan materias que han sido también objeto de una ley estatal podrán ser pura y simplemente inaplicadas por el juez ordinario, sin consulta alguna al juez constitucional, en virtud de la cláusula de prevalencia del art. 149.3, asumiendo así, aunque sólo sea con referencia al caso concreto, el control de la ley". El razonamiento anterior ha sido desarrollado por J. GARCÍA TORRES, "La cláusula de prevalencia y el poder judicial», en Estudios sobre la Constitución española. Homenaje al Profesor Eduardo Garcla de Enterrfa, vol. I, cit., págs. 569 y siguientes.
} 
piezas del sistema jurídico mecanismos que alivien la agobiante labor del Tribunal Constitucional, agobio que sin duda lastra la eficacia de su funcionamiento.

Según creo, no parece que haya suficiente fundamento constitucional para sostener que la ley básica estatal tiene «más valor» que la ley autonómica complementaria, que sería siempre una Ley «de menor valor». La superioridad de los intereses generales cuya salvaguarda es función de la ley básica estatal no se corresponde, en el plano formal de las relaciones internormativas, con un mayor valor o una mayor fuerza normativa (que vincule más fuertemente al juez) de la ley estatal. Ambas leyes - la básica estatal y la complementaria autonómicatienen el mismo rango, la misma fuerza y el mismo valor normativo, y sólo se diferencian por el objeto o la materia que una y otra pueden regular conforme a las reglas de distribución de competencias legislativas que se contienen en el bloque de la constitucionalidad (Constitución y Estatutos, principalmente). Ello explica que el art. 153 a) de la Constitución atribuya en exclusiva al Tribunal Constitucional el control de las "disposiciones normativas con fuerza de ley" de las Comunidades Autónomas. Y esa misma razón - la igualdad formal entre ambas normas- justifica también que el citado art. 163 obligue a los órganos judiciales ordinarios a plantear la cuestión de inconstitucionalidad cuando consideren que "una norma con rango de Ley" de cuya validez depende el fallo pueda ser contraria a la Constitución, sin distinguir entre leyes estatales y autonómicas ni exceptuar los supuestos de grupos normativos integrados por leyes básicas del Estado y leyes complementarias de las Comunidades Autónomas, y una vez que "por vía interpretativa no sea posible la acomodación de la norma al ordenamiento constitucional», como se ocupa de precisar el art. 5.3 LOPJ.

Aceptar, por tanto, la vía auxiliar del control judicial ordinario en este tipo de colisiones normativas significa pura y simplemente admitir la posibilidad de sustituir el principio de competencia por el principio de prevalencia, dando más valor preceptivo al art. 149.3 que a los artículos 153 a) y 163 de la Constitución, pues según ello el juez ordinario podría aplicar la ley básica e inaplicar la ley complementaria, con independencia de que la primera pudiera ser inválida por haber incurrido en vicio de incompetencia. De otro lado, aunque en la tesis que aquí se combate se declare lo contrario, dar más valor o fuerza (pues tal cosa es la prevalencia) a la ley básica estatal que a la ley complementaria autonómica supone integrar aquélla de facto en el bloque de la constitucionalidad, no ciertamente para sancionar la invalidez de la ley autonómica y expulsarla del ordenamiento, potestad ésta vedada al juez ordinario; pero sí para inaplicarla y privarla de eficacia normativa por su presunto contraste con una ley "superior» (aunque, he aquí 
la paradoja, del mismo rango). Lo que equivale asimismo a sustituir, aunque también se niegue, el principio de competencia por el de jerarquía en las relaciones entre uno y otro tipo de leyes, utilizando para ello inesperadamente el tradicional esquema de relaciones entre la «ley» y el «reglamento», pues así como el juez, vinculado más fuertemente a la ley, debe inaplicar el reglamento ilegal jerárquicamente subordinado (art. $6 .^{\circ} \mathrm{LOPJ}$ ), ese mismo juez, más fuertemente vinculado a la ley básica estatal, debe, o al menos puede ${ }^{10}$, según esta tesis, inaplicar la "funcionalmente subordinada» ley autonómica de desarrollo que la contradiga. Todo ello con olvido, de nuevo, de los arts. 153 a) y 163 de la Constitución.

Para rechazar las anteriores objeciones a la tesis del control judicial no basta, me parece, con advertir que en este caso el juez ordinario no se pronuncia sobre la validez o invalidez de la ley autonómica, sino que se limita sólo a negarle eficacia. A diferencia de lo que ocurre en los supuestos de legislación concurrente en los que el juez ha de elegir, entre dos normas válidas en conflicto, la que resulte favorecida por la regla de la prevalencia, en la legislación compartida la eventual inaplicación de la ley autonómica implica siempre un juicio previo acerca de su invalidez por entender que contradice la regulación básica reservada a la ley estatal. De no advertir contradicción entre las dos leyes o pudiendo resolver sus aparentes antinomias mediante el uso de las reglas generales de interpretación, el juez ha de aplicar ambas al caso concreto, y ha de hacerlo porque son válidas y compatibles entre sí, y sobre él pesa «el deber inexcusable de resolver en todo caso los asuntos de que conozca (n), ateniéndose al sistema de fuentes establecido" (art. 1.7 Código Civil). Del mismo modo, si el juez decidiera inaplicar la ley autonómica ello sólo podría ocurrir porque la considera incompatible -luego inválida - con la ley básica estatal, pero al no estar habilitado para declarar formalmente tal invalidez, función ésta reservada al Tribunal Constitucional, habría de limitarse a operar en el terreno de la eficacia, dándose así un evidente paralelismo, también desde este ángulo, con el control de los Reglamentos ilegales por los jueces y tribunales no pertenecientes al orden contencioso-administrativo, los cuales, una vez comprobada la invalidez de una norma reglamentaria por infringir la ley, no pueden declarar su nulidad, pero sí negarle eficacia mediante su inaplicación al caso concreto. Todo lo cual significa que el control judi-

${ }^{10} \mathrm{El} \mathrm{juez} \mathrm{ordinario} \mathrm{tiene} \mathrm{siempre} \mathrm{abierta} \mathrm{la} \mathrm{posibilidad} \mathrm{de} \mathrm{suscitar} \mathrm{la} \mathrm{cuestión} \mathrm{de} \mathrm{incons-}$ titucionalidad. Por ello, para los partidarios de la tesis de control judicial, no estaría, en rigor, obligado a inaplicar la ley autonómica contradictoria con la ley básica estatal, sino sólo facultado a hacerlo, pudiendo en todo caso renunciar a su propio control y plantear la colisión normativa ante el Tribunal Constitucional. 
cial de eficacia de las normas es inevitablemente un control de validez, y que por ello mismo la ley autonómica que el juez ordinario inaplicara quedaría de facto degradada y tratada como si fuera una simple norma subordinada a la ley básica estatal.

Nada de ello tiene encaje en nuestro sistema constitucional. Como ya se ha dicho, la ley autonómica no es inferior en rango, valor o fuerza a la ley estatal ni cabe negarle eficacia normativa sin que medie una previa declaración de invalidez ${ }^{11}$, declaración que sólo al Tribunal Constitucional corresponde hacer a requerimiento del órgano judicial que suscite la duda de su inconstitucionalidad por infracción de la ley básica estatal y consiguiente alteración del orden constitucional de competencias normativas.

Desde la perspectiva del control de constitucionalidad, es indiferente que la ley autonómica se haya producido en el ejercicio de una competencia normativa exclusiva o de una competencia normativa compartida con la ley básica estatal. En ambos supuestos, la norma autonómica resultante es en todo caso una ley, es decir, una norma cuyo control de constitucionalidad, que abarca tanto su validez como su eficacia (el art. 153 de la Constitución no distingue entre ambos planos), está reservado en exclusiva, como en todos los demás tipos de leyes, al Tribunal Constitucional ${ }^{12}$, sin espacio posible para tareas de "colaboración" por los órganos judiciales ordinarios. Estos pueden y deben controlar la vigencia de las leyes autonómicas que hayan de aplicar, pero no pueden ni deben controlar la validez y la eficacia de las leyes autonómicas de cuya vigencia no haya duda. Si dudan de su constitucionalidad por una eventual contradicción con las leyes básicas que complementan o desarrollan, no hay otro camino que el planteamiento de la correspondiente cuestión.

Este recto entendimiento de la relación que une al juez ordinario con la ley autonómica —en cuya virtud tiene poder para declarar su

\footnotetext{
11 La afirmación del texto debe entenderse referida, claro está, a la eficacia definitiva de la ley autonómica, sin perjuicio de las reglas que regulan su eventual ineficacia temporal durante el proceso constitucional.

12 Sería, por lo demás, altamente paradójico que los conflictos normativos entre leyes estatales básicas y leyes autonómicas complementarias que hasta el momento el Tribunal Constitucional ha resuelto siempre mediante la aplicación del principio de competencia, sin necesidad de utilizar en ningún caso la cláusula de prevalencia del Derecho estatal, fueran a partir de ahora zanjados por los jueces ordinarios, en su tarea de colaboración auxiliar con la jurisdicción constitucional que algunos preconizan, mediante la aplicación de esta última regla, la de la prevalencia (que el Tribunal Constitucional ignora en estos conflictos), en detrimento del principio de competencia.
} 
REALA 258 (ABRIL-JUNIO, 1993)

falta de vigencia pero no su invalidez o ineficacia- permite reconocer también con toda naturalidad la potestad de la jurisdicción ordinaria para aplicar la ley estatal en detrimento de la ley autonómica en aquellos casos, ya señalados por la doctrina 13 , en que la colisión normativa tiene lugar como consecuencia de modificaciones en la legislación básica preexistente. Y ello justamente porque en tales supuestos la antinomia no se plantea en términos de validez sino de vigencia de las normas en conflicto: en la secuencia temporal del contraste normativo, la ley básica posterior contradice y, por tanto, deroga directamente la ley básica anterior e indirectamente también la ley autonómica que complementaba o desarrollaba aquélla y que, carente ahora de soporte legislativo básico, queda desplazada y sin vigor alguno por obra de la nueva (y válida) ley básica estatal. En tal operación de control judicial no hay, como se ve, juicio alguno sobre la validez de las normas en conflicto, sino sólo escrutinio de las normas derogadas, según la regla general del art. 2.2 del Código Civil, y elección de la norma vigente y, por tanto, aplicable al caso.

13 FERNÁNDEZ FARRERES, op. cit., págs. 565-566, nota 41; LASAGABASTER HERRARTE, op. cit., págs. 145 y siguientes. 